\title{
Dimensions of Human Adult Tricuspid Valve Annulus in the Embalmed Cadavers
}

\author{
Babita Kujur ${ }^{1}$, Narendra Thakur ${ }^{2}$ and Renu Prasad ${ }^{3}$ \\ ${ }^{l}$ Junior Resident, Anatomy, Rajendra Institute Of Medical Sciences, Ranchi, Jharkhand, India \\ ${ }^{2}$ Professor, Anatomy, Rajendra Institute Of Medical Sciences, Ranchi, Jharkhand, India \\ ${ }^{3}$ Professor And HOD, Anatomy, Rajendra Institute Of Medical Sciences, Ranchi, Jharkhand, India
}

\begin{abstract}
Introduction: In human heart, right atrio-ventricular orifice is guarded by tricuspid valve, which lies at the junction of right atrium and right ventricle of the heart controlling and directing unidirectional blood flow during ventricular diastole. Irreparable damage to tricuspid valve calls for its replacement using prosthetic valves. Prosthesis of these synthetic valves need detail knowledge of tricuspid orifice. In present study an attempt was made to study the dimensions of tricuspid orifice.
\end{abstract}

Materials and Method: The present work was done by dissecting 42 formalin fixed adult human hearts. The sex of human was not considered.

Tricuspid orifice was cut opened in these specimen and following measurements were taken (a) circumference of annulus of tricuspid valve (b) diameter of tricuspid valve in two vertically perpendicular plane.

Results: The circumference of the tricuspid valve annulus ranged from $7.9 \mathrm{~cm}$ to $12 \mathrm{~cm}$, average was 9.7 $\mathrm{cm} \pm 1.029$ and median $-9.5 \mathrm{~cm}$. The diameter measured in two separate perpendicular planes at maximally separated points ranged from $1.3 \mathrm{~cm}$ to $4.5 \mathrm{~cm}$. In one plane, mean diameter was $2.1 \pm 0.43 \mathrm{~cm}$ and median was $2 \mathrm{~cm}$. In second plane, mean diameter was $3.03 \pm 0.54 \mathrm{~cm}$ and median was $2.9 \mathrm{~cm}$.

Conclusion: These data may be useful in designing the prosthetic valves.

Keywords: Tricuspid valve, right ventricle, human heart, circumference, diameters

\section{Introduction}

Rapid progress in the field of interventional cardiology has caused research in the field of morphometry of the heart to be in constant demand. The heart is a pair of valved muscular pump combined in a single organ (1). Despite intense interest in cardio anatomy there are many issues to be examined with great care. The problem of the morphology of the atrio-ventricular orifice is still an open question. The tricuspid valve orifice is best seen from the atrial aspect. It is roughly triangular, its margins are described as anterosuperior, inferior and septal, corresponding to the lines of attachment of valvular cusps. The tricuspid valve guards the right atrio-ventricular orifice. It has three, roughly triangular shaped cusps that projects into the right ventricle anterior (superior), posterior (inferior) and septal. The tricuspid valvular complex comprises of the following: orifice and its associated annulus, 3 leaflets, supporting tendinous cords and papillary muscles. Harmonious interplay of all these together with the atrial and ventricular myocardial masses depends on the conducting tissues and the mechanical cohesion provided by the fibro-elastic cardiac skeleton (1). The AV valve develops from the excavation of the supporting ventricular myocardium (2). The tricuspid valve is more differentiated during evolution than the mitral valve $(3,4,5,6)$

According to Silver et al (1971) (7) - Circumference of tricuspid valve annulus measures around $11.4 \mathrm{~cm}(114 \pm 11 \mathrm{~mm})$ in males and $10.8 \mathrm{~cm}(108 \pm 13 \mathrm{~mm})$ in females and is best seen from its atrial aspect. It is roughly triangular and its margins are described as antero-superior, inferior and septal corresponding to the lines of attachment of the valvular leaflets. The dynamic progress in therapeutic and diagnostic cardio invasive procedure implies a marked rise in interest in studies of cardiac anatomy and it is reasonable therefore to resume research on the tricuspid valve. Primary valve replacement of tricuspid valve is preferred to valve repair in extensive tricuspid valve destruction as a result of acute endocarditis (Lange et al. 1996)(8). However knowledge and interest in tricuspid valve has always lagged behind that of mitral valve $(9,10,11)$ The work on normal dimensions of tricuspid valve is surprisingly scanty. Hence this work will be of great help for both the anatomist as well as cardiac surgeons.

\section{Materials and methods}

The present work was carried out in department of Anatomy, Rajendra Institute of Medical Sciences (RIMS), Ranchi, Jharkhand. This work was done by dissecting 42 formalin fixed adult human hearts. The sex of human was not considered. 
Instruments used

Disposable gloves, scissors, a pair of toothed forceps, a pair of plane forceps, malleable aluminum wire, a pair of dividers, ruler, digital camera

\section{Collection of specimens}

he adult human hearts were obtained by dissecting formalin fixed cadavers allotted to the undergraduate medical students of department of anatomy, RIMS, Ranchi, Jharkhand. Few human hearts, used earlier by a senior post graduate student of RIMS, for his dissertation work on coronary arteries were also utilized for the present study. Some of the hearts were also collected from the Department of forensic medicine and toxicology, RIMS, Ranchi.

\section{Method of dissection of already removed hearts}

Dissection was performed according to the standard techniques as mentioned in Cunningham's manual of practical Anatomy volume 2 .

Exposure of tricuspid valve

To expose the tricuspid valve, incision was begun at the inferior vena cava with scissors and cut into the right atrium staying about 0.5 to $1 \mathrm{~cm}$ above the tricuspid valve annulus. Blood clots if present were washed out from the atrial chamber.

he circumference of the tricuspid valve was measured with the help of a malleable aluminum wire. The wire was placed along the boundary of the annulus conforming to its shape and is marked were the ends of the wire meet and then measured with a ruler, after it was straightened. The method of measurement is shown in Figure 1. The values were noted and tabulated. The diameter of the tricuspid valve annulus were measured in two separate perpendicularly oriented planes, at the maximally separated points using a pair of divider with fine points and ordinary ruler with subdivision of $0.1 \mathrm{~cm}$. The method of measurement is shown in Figure 2.The parameters applied for analysis of the values are - Mean \pm Standard deviation and Median.

\section{Results}

Studies were done under following headings -a) Circumference of the tricuspid valve annulus b) Diameter of tricuspid valve annulus in two separate perpendicularly oriented planes at maximally separated points.

\section{Circumference of the tricuspid valve annulus}

In present study, the circumference of the tricuspid valve annulus ranged from $7.9 \mathrm{~cm}$ to $12 \mathrm{~cm}$, maximum circumference was $12 \mathrm{~cm}$, minimum circumference $-7.9 \mathrm{~cm}$, average circumference $-9.7 \mathrm{~cm}$, standard deviation - 1.029and median - 9.5 In $19.04 \%$ of cases the circumference of the tricuspid valve annulus ranged from 7.6 to $8.5 \mathrm{~cm}$, in $28.6 \%$ of cases the circumference ranged from 8.6 to $9.5 \mathrm{~cm}$, in $28.6 \%$ of cases it ranged from 9.6 to $10.5 \mathrm{~cm}$, in $21.4 \%$ of cases it ranged from 10.6 to $11.5 \mathrm{~cm}$ and in $2.38 \%$ of cases the circumference ranged from 11.6 to $12.5 \mathrm{~cm}$.

\section{Diameter of the tricuspid valve annulus}

The diameter of the tricuspid valve annulus was taken in two separate perpendicularly oriented planes at the maximally separated points. It ranged from $1.3 \mathrm{~cm}$ to $4.5 \mathrm{~cm}$.Diameter in $1^{\text {st }}$ plane Maximum Diameter was $3.4 \mathrm{~cm}$, Minimum Diameter $-1.3 \mathrm{~cm}$, Mean Diameter $-2.1 \mathrm{~cm}$, Standard Deviation -0.43 and Median -2 Diameter in $2^{\text {nd }}$ plane Maximum Diameter $-4.5 \mathrm{~cm}$, minimum Diameter $-1.9 \mathrm{~cm}$, mean Diameter $-3.03 \mathrm{~cm}$, Standard Deviation -0.546 and Median - 2.9. In $20.2 \%$ of cases the diameter ranged from 1.0 to $1.9 \mathrm{cms}$, in 50 $\%$ of cases it ranged from 2.0 to $2.9 \mathrm{cms}$, in $26.1 \%$ of cases it ranged from 3.0 to $3.9 \mathrm{cms}$ and in $3.57 \%$ of cases it ranged from 4.0 to $4.9 \mathrm{cms}$.

Graph no.1 and Graph no. 2 shows the percentage of cases having circumference and diameter in following range respectively.

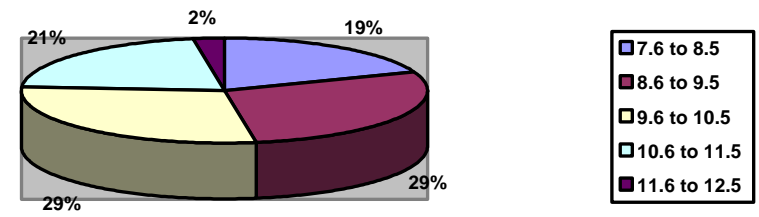

Graph no.1 


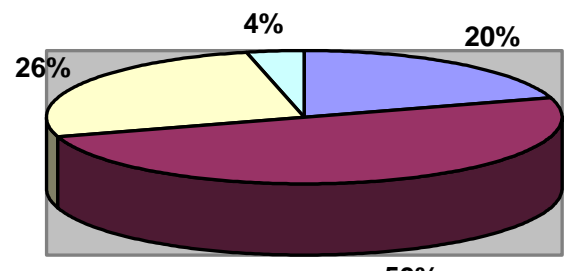

\begin{tabular}{|l|}
$\square 1.0$ to 1.9 \\
$\square 2.0$ to 2.9 \\
$\square 3.0$ to 3.9 \\
$\square 4.0$ to 4.9
\end{tabular}

$50 \%$

Graph no.2

\section{Discussion}

The tricuspid valve is a heterogeneous structure and is of great clinical importance because of the progress made in the operative techniques and invasive cardiac surgery including the partial transfer of the posterior leaflet of the tricuspid valve for repair of mitral valve $(12,13)$ tricuspid replacement $(14,15)$, complications after heart transplantation (16), invasive cardiology(17) and valvuloplasty(18). The tricuspid valve is often called the "forgotten valve" or "lost valve" because it is relatively understudied relative to the other cardiac valves. Hence the present study was done to serve the above mentioned purposes. Louis et al in 1971(19) suggested that the accurate knowledge of the structure of the valves in the human heart in humans is of prime importance for 3 very practical reasons - a) The various anatomical peculiarities in the valve leaflets suggest an explanation for at least some of the mechanical components entering into the localization of inflammatory, as well as degenerative (atherosclerotic) processes in these sites. b) The insight into the pathological processes thus obtained helps one differentiate these lesions from one another. c) One is better able to cope with the long disputed question as to whether or not blood vessels or myocardium normally exist in valves. There can be marked variation in the anatomy of normal tricuspid valve complex, which must be understood to differentiate it from pathological malformation.

\section{Circumference}

Tei C et al in 1982(20) conducted a study on the size and motion of tricuspid valve annulus in normal subjects and patients with tricuspid regurgitation. They found that the mean maximum annular circumference and area were $11.3 \pm 0.9 \mathrm{~cm}$ and $11.3 \pm 1.8 \mathrm{~cm}^{2}$ in normal subjects. They were significantly greater in tricuspid regurgitation. For anatomical correlations, measurements of the tricuspid annular circumference were made at autopsy in 18 hearts without underlying valvular disease. The annular circumference was measured in fresh and fixed state. The measurement in fresh state was $13.5 \pm 0.8 \mathrm{~cm}$ and in fixed state was $12.0 \pm 0.8 \mathrm{~cm}$. The values measured in fixed state were more similar to measurements obtained by echocardiography in a group of normal subjects. In 1971, Silver et al (7) reported tricuspid valve circumference to be $11.4 \pm 1.1 \mathrm{~cm}$ in males and $10.8 \pm 1.3 \mathrm{~cm}$ in females. Motabagani in 2006(8), in his study of 40 human tricuspid valves has found that the circumference of tricuspid valve ranged from 11.8 to $13.9 \mathrm{~cm}$ in men and 11.3 to $12.4 \mathrm{~cm}$ in females.

In a study conducted on 96 human hearts by Skwarek M et al, in 2008 (11), the circumference of the tricuspid valve ranged from $10.72 \pm 1.67 \mathrm{~cm}$ to $12.09 \pm 2.09 \mathrm{~cm}$ in men and from $10.40 \pm 1.67 \mathrm{~cm}$ to $11.07 \pm 1.43$ in women. R. Kalyani et al in 2012(21) found that the circumference of the tricuspid valve ranged from $8.93 \pm 0.7 \mathrm{~cm}$ to $10.7 \pm 1.06 \mathrm{~cm}$ in males and from $8.59 \pm 0.67 \mathrm{~cm}$ to $10.4 \pm 0.5 \mathrm{~cm}$ in females. In present study, the circumference of the tricuspid valve annulus was as follows:

Range -7.9 to $12 \mathrm{~cm}$, maximum circumference $-12 \mathrm{~cm}$, minimum circumference $-7.9 \mathrm{~cm}$, average circumference $-9.7 \pm 1.029 \mathrm{~cm}$, median -9.5 . In $19.04 \%$ of cases the circumference of the tricuspid valve annulus ranged from 7.6 to $8.5 \mathrm{~cm}$, in $28.6 \%$ of cases the circumference ranged from 8.6 to $9.5 \mathrm{~cm}$, in $28.6 \%$ of cases it ranged from 9.6 to $10.5 \mathrm{~cm}$, in $21.4 \%$ of cases it ranged from 10.6 to $11.5 \mathrm{~cm}$ and in $2.38 \%$ of cases the circumference ranged from 11.6 to $12.5 \mathrm{~cm}$.

Table no. 1: Comparison of the circumference of tricuspid valve annulus with other studies.

\begin{tabular}{|l|l|l|}
\hline $\begin{array}{l}\text { Sl. } \\
\text { No. }\end{array}$ & Studies & $\begin{array}{l}\text { Circumference of TV annulus } \\
\text { (in cms) }\end{array}$ \\
\hline 1 & Present study & $9.7 \pm 1.029 \mathrm{~cm}$ \\
\hline 2 & Tie C. et al(1982) & $11.3 \pm 0.9$ \\
\hline 3 & Silver et al(1971) & $11.4 \pm 1.1 \mathrm{~cm}$ in males \\
& & $10.8 \pm 1.3 \mathrm{~cm}$ in females. \\
\hline 4 & Motabagani (2006) & 11.8 to $13.9 \mathrm{~cm}$ in males \\
& & 11.3 to $12.4 \mathrm{~cm}$ in females. \\
\hline
\end{tabular}


Dimensions Of Human Adult Tricuspid Valve Annulus In The Embalmed Cadavers

\begin{tabular}{|l|l|l|}
\hline 5 & Skwarek M et al( 2008) & $\begin{array}{l}10.7 \text { to } 12.0 \mathrm{~cm} \text { in males } \\
10.4 \text { to } 11 \mathrm{~cm} \text { in females }\end{array}$ \\
\hline 6 & R. Kalyani et al (2012) & 8.9 to $10.7 \mathrm{~cm}$ in males \\
& & 8.5 to $10.4 \mathrm{~cm}$ in females \\
\hline
\end{tabular}

\section{Diameter}

In 1994 Singh B and Mohan J.C(22) determined the atrioventricular orifice area in 78 healthy subjects aged 2 months to 50 years, by cross sectional and Doppler echocardiography to establish normal values and their relationship with body surface area. Mitral valve orifice area was determined (i) by direct planimetry which was $3.37 \pm 1.13 \mathrm{~cm}^{2}$, the range being $0.52-5.6 \mathrm{~cm}^{2}$ and (ii) by continuity equation by which the area was $3.62 \pm 1.08 \mathrm{~cm}^{2}$ the range being $0.66-7.2 \mathrm{~cm}^{2}$. Tricuspid valve orifice area $\left(4.07 \pm 1.5 \mathrm{~cm}^{2}\right.$; range: $\left.0.62-7.20\right)$ and by continuity equation had a close correlation with mitral valve orifice area(r-0.76, $\mathrm{p}<0.001)$. Mitral and tricuspid valve orifice areas were significantly correlated to body surface area ( $\mathrm{r}-0.85$ and 0.77 respectively), left and right ventricular outflow diameters ( $\mathrm{r}=0.90$ and 0.79$)$ respectively), and age ( $\mathrm{r}=0.70$ and 0.61 respectively). These data provide normal values for AV valve orifice area in normal subjects with a wide range of body surface area and support the practice of indexing valve area by body surface area. In 2005, John F. Secombe et al (23) studied the quantitative morphological study of the normal human tricuspid valve at autopsy of 24 cases and found that the mean tricuspid valve diameter was $2.13 \pm 0.03 \mathrm{~cm}$. In the present study, the diameter of tricuspid annulus in two separate perpendicularly oriented planes at maximally separated points: Range of diameter -1.3 to $4.5 \mathrm{~cm}$ Diameter in $1^{\text {st }}$ plane Maximum Diameter $-3.4 \mathrm{~cm}$, minimum diameter $-1.3 \mathrm{~cm}$, mean diameter $-2.1 \mathrm{~cm}$, standard deviation -0.43 , median 2 Diameter in $2^{\text {nd }}$ plane Maximum Diameter $-4.5 \mathrm{~cm}$, minimum diameter $-1.9 \mathrm{~cm}$, mean diameter $-3.03 \mathrm{~cm}$, standard deviation -0.546 median -2.9 In $20.2 \%$ of cases the diameter ranged from 1.0 to $1.9 \mathrm{cms}$, in $50 \%$ of cases it ranged from 2.0 to $2.9 \mathrm{cms}$, in $26.1 \%$ of cases it ranged from 3.0 to $3.9 \mathrm{cms}$ and in $3.57 \%$ of cases it ranged from 4.0 to $4.9 \mathrm{cms}$.

Table no. 2: Showing comparison of diameter of tricuspid valve annulus with other studies.

\begin{tabular}{|l|l|l|}
\hline Sl. No. & Studies & Diameter of TV annulus(in cm) \\
\hline 1. & Present study & $2.1 \pm 0.43(\mathrm{D} 1)$ \\
& & $3.03 \pm 0.546(\mathrm{D} 2)$ \\
\hline 2. & Gray's Anatomy & 3.43 to3.63 \\
\hline 3. & Singh B and Mohan JC(1994) & 2.26 \\
\hline 4. & John F. Secombe et al(2004) & $2.13 \pm 0.03$ \\
\hline
\end{tabular}

\section{Conclusion}

The anatomy of tricuspid valve complex is highly sophisticated, but accurate knowledge of its a morphology and morphometry is extremely important, not only to understand the normal function of valves but also to improve our understanding of the pathophysiological mechanism underlying the various tricuspid valve diseases and potentially suggest ways to improve surgical treatment related to it. From the above result it is concluded that this study will be helpful to the cardiovascular surgeons as there is little data available on morphometry of tricuspid valve. These data may be helpful in designing the prosthetic valves for replacement of extensively damaged tricuspid valve.

\section{References}

[1]. Susan Standing, Gray's Anatomy, The Anatomical Basis of Medicine and surgery 39th Edition, 2005; Elsivier Churchill Livingstone, P 1003-1004.

[2]. Steding G., Seidl W. (1993) Cardio-vaskuläres System. In: Hinrichsen K.V.: Human embryologie. Springer-Verlag, Berlin, Heidelberg. Pp. 205-294.

[3]. Anderson RH, Benson R, Wilcox MD (2000) Reply. Ann Thorac Surg, 69: 1990

[4]. 4)Lamers WH, Virágh S, Wessels A, Moorman AFM,Anderson RH (1995) Formation of the tricuspid valve in the human heart. Circulation 91, 111-121

[5]. Szostakiewicz-Sawicka H, Grzybiak M (1981) Zgodność rozwoju osobniczego niektórych cech budowy serca z przypuszczalnym kierunkiem ich rozwoju w antropogenezie. Morfologia, podręczniki, skrypty AWF. Seria: Monografie, 199: 9-16.

[6]. Szostakiewicz-Sawicka H (1967) Zastawka przedsionkowo- komorowa prawa u naczelnych. Rozprawa habilitacyjna.

[7]. Acta Biol Med Soc Sc Gedan, 11: 545-589.

[8]. Silver MD, Lam JHC, Ranganathan N, Wigle ED. Morphology of the human tricuspid valve. Circulation. 1971;43: 333-348

[9]. Mohamed A.B. Motabagani; Comparative Anatomical, Morphometric and Histological Studies of the Tricuspid Valve-Complex in Human and Some Mammalian Hearts. J.Anat.Soc. India. (2006) 55: 1-23

[10]. Rogers JH, Bolling SF. The Tricuspid Valve: Current Perspective and Evolving Management of Tricuspid Regurgitation. Circulation. 2009; 119:2718-25

[11]. Joudinaud TM, Flecher EM, Duran CM. Functional Terminology for the Tricuspid Valve. J Heart Valve Dis. 2006;15:382-8

[12]. Skwarek M, Hreczecha J, Dudziak M, Jerzemowski J, Grzybiak M. Morphometeric features of right atrioventricular orifice in adult human hearts. Folia Morphol 2008; 67: 53-7

[13]. Hvass U, Juliard JM, Assayag P, Laperche T, Pansard Y, Chatel D (1996) Tricuspid autograft for mitral-valve repair. Lancet, 347: 659-661

[14]. Khoury GE, d'Udekem Y, Noirhomme P, Verhelst R, Rubay J, Dion R (2000) Transfer of the posterior leaflet of the tricuspid valve to the mitral valve. J Heart Valve Dis, 9: 350-352. 
[15]. Cardarelli MG, Gammie JS, Brown JM, Poston RS, Pierson RN 3rd, Griffith BP (2005) A novel approach to tricuspid

[16]. valve replacement: the upside down stentless aortic bioprosthesis. Ann Thorac Surg, 80: 507-510.

[17]. Carrier M, Hebert Y, Pellerin M, Bouchard D, Perrault LP, Cartier R, Basmajian A, Page P, Poirier NC (2003) Tricuspid valve replacement: an analysis of 25 years of experience at a single center. Ann. Thorac. Surg, 75: 47-50

[18]. Crumbley AJ, Van Bakel AB (1994) Tricuspid valve repair for biopsy-induced regurgitation after cardiac transplantation. Ann Thorac Surg, 58: 1156-1160.

[19]. Langberg JJ, Man KC, Vorperian VR, Williamson B., Kalbfleisch SJ, Strickberger SA, Hummel JD, Morady F (1993) Recognition and catheter ablation of subepicardial accessory pathways. JACC 22: 1100-1104.

[20]. Sharieff S, Sagir T, Shah-e-Zaman K (2005) Concurrent percutaneous valvuloplasty of mitral and tricuspid valve stenoses. J Invasive Cardiol, 17: 340-342.

[21]. Louis Gross MA, Kugel. Topographic Anatomy and histology of the valves in the Human Heart, Anatomy and Histology of valves 1971; P 445-475.

[22]. Tei C, JP Pilgrim, PM Shaw, JA Armiston and M Wong. The tricuspid valve annulus: Study of size and motion in normal subjects and in patients with tricuspid regurgitation, Circulation, Volume 66: 665-671.

[23]. R. Kalyani, M.J. Thej, K. Prabhakar, T.K. Venkatesh, A.K. Thomas and J.Kiran(2012). Morphometric analysis of tricuspid valve: An Indian perspective. J. Nat Sci Biol Med 2012 Jul-dec; 3(2): 147-151.

[24]. Singh B, Mohan JC; Atrioventricular valve orifice areas in normal subjects: determination by cross sectional and Doppler echo cardiography: Int J Cardiol 1994 March 15; 44(1): 85-91.

[25]. John F. Seccombe, Donald R Cahill, William D. Edwards. Quantitative Morphology of the normal human tricuspid valve: Autopsy study of 24 cases. Clinical Anatomy 2002 Jan; 6 (4): 203-212.
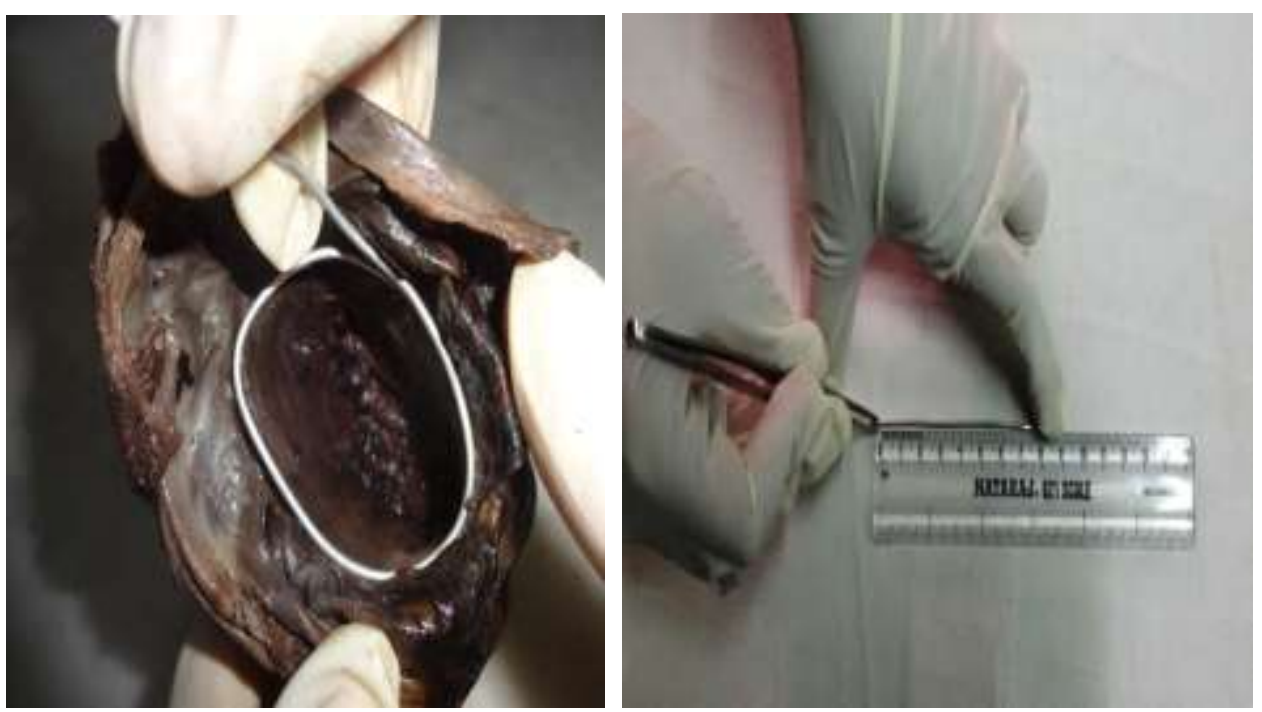

Figure no. 1: Showing method of measurement of circumference of Tricuspid valve annulus.
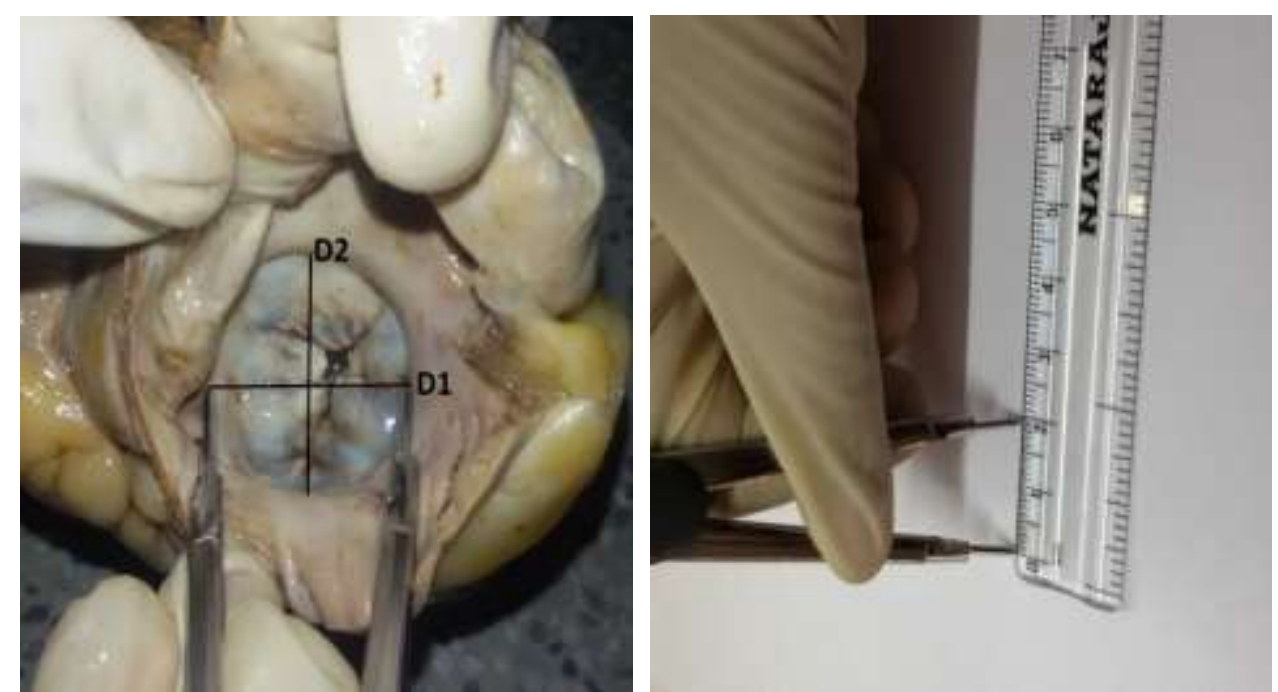

Figure No.2: Showing method of measurement of diameter of Tricuspid valve annulus. 